\title{
La Paz que la Universidad debe ayudar a encontrar ${ }^{*}$
}

\author{
Por el Reverendísimo Padre FELIPE E. MAC GREGOR, S. J. \\ Rector de la Pontificia Universidad Católica del Perú
}

Para señalar la misión y la dirección del esfuerzo de la Universidad en la búsqueda de la paz, hay que distinguir los varios contenidos intelectuales, históricos, socio-culturales con que la idea o la realidad social de la paz se ha enriquecido.

Es obvio que "paz" se ha interpretado y ha significado para muchos en la historia la antítesis de guerra.

Es también cierto como en el curso de los siglos cristianos y en los que los precedieron y de los que tenemos manera de conocer su pensamiento. la paz se refiere también a la actitud del hombre frente al hombre. El pacífico de que habla la bienaventuranza, el amador de la paz, ha sido descrito en estas líneas:

"Al ser los hombres por naturaleza sociales, deben convivir unos con otros y procurar cada uno el bien de los demás. Por esto, una convivencia humana rectante ordenada exige que se reconozcan y se respeten mutualmente los derechos y los deberes. De aquí se sigue también el que cada uno deba aportar su colaboración generosa para procurar una convivencia civil en la que se respeten los derechos y los deberes con diligencia y eficacia crecientes.

No basta, por ejemplo, reconocer al hombre el derecho a las cosas necesarias para la vida si no se procura, en la medida posible, que el hombre posea con suficiente abundancia cuanto toca a su sustento".

En torno de estos dos polos: la paz en la acción de las sociedades y la paz en la acción de los hombres, se han agrupado los principales calificativos que la paz tiene:

(*) Trabajo presentado a la Conferencia de la Asociación de las Universidades en busca de la Paz, reunida en Lima. 


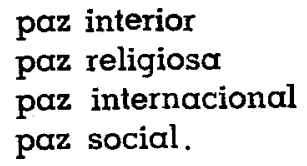

La Universidad tiene relación muy clara y expresa a cada uno de los diversos aspectos de esta incompleta enumeración de los apelativos de la paz.

Deseo subrayar dos de ellos no solo porque dicen relación más directa a nuestro quehacer de universitarios, sino porque la tolerancia religiosa se observa respetuosamente, por lo menos en la comunidad occidental de nuestro mundo, y de la paz internacional se ocupa la gran creación del deseo y la conciencia pacífica del hombre moderno: la Organización de las Naciones Unidas.

Son las dos acepciones que vamos a considerar: la paz interior y la paz social; es la búsqueda de la segunda la que ocupará más nuestra reflexión sin dejar, sin embargo, de mencionar, al pasar y sin detenernos casi, la importancia de la primera.

La misión de la Universidad es la búsqueda y la comunicación del saber; la relación de ese saber a la integridad del hombre es el pre-requisito y la condición de su paz. Cuando se expresa dinámicamente la visión del mundo y cuando la luz de la inteligencia domina las fuerzas interiores y mide lo medible de su dominio de las fuerzas exteriores, el hombre tiene paz.

Hay que subrayar la importancia de la luz intelectual para la entereza moral, como para la visión de la armonía con el mundo que constituye la paz.

La reflexión sobre estos temas es rica e inspira consideraciones en torno de los problemas concretos que serón debatidos en estos días acerca, por ejemplo, del contenido de los programas de estudios, la orientación de los cursos, etc., no puede siquera concebirse que sea la paz social el objeto de la formación universitaria, sino que en el orden de primacía tiene un puesto sumamente elevado la reflexión sobre la paz interior.

Por voluntad de los auspiciadores de nuestra Institución el cometido principal de nuestra búsqueda es la paz social: la paz considerada como la solución de las tensiones sociales que agobian a los hombres.

\section{La tensión social, la revolución y la evolución social}

La tensión social no es el justo y natural afán de los grupos que en su conciencia y esfuerzo de progresar encuentran la resistencia de los otros y se esfuerza por superarla: esa tensión es la fuente natural del progreso.

Heráclito condena a Homero porque, a pesar de ser el más sabio de los griegos, se dejó engañar por las apariencias y no comprendió que la tensión es esencial, y llegó a formular una plegaria para que desapareciera del mundo. 
- Lo que está en oposición tiene concordia y de las cosas que difieren procede la más hermosa armonía, (Heráclito, Fragmento 8).

- No entiendes como lo que es diferente consigo mismo está $\alpha$ cordado: la armonía consiste en tensiones opuestas como las del arco y la lira. (Fragmento 51).

- Uno debe saber que la guerra es universal y que la jurisdicción del todo es la tensión: lo que acontece sucede por tensión y necesidad. (Fragmento 80).

La existencia pues depende de la tensión de las cosas opuestas y en la proporción de tensiones consiste lo "recto" y el ímpetu que promueve las tensiones es inmanente a todas las cosas; la guerra es el padre de todo $y$ el rey de todo.

Pero no son estas tensiones que producen lo recto y engendran la armonía las que causan el desequilibrio social.

Las tensiones a que nos referimos son las que envuelven una parte del todo social en si misma y enconan el esfuerzo por el equilibrio tornándolo en resentimiento, frustración, angustia o sopor que casi coincide con el embrutecimento $\rightarrow$ convirtiendo el esfuerzo de otra parte en abuso de poder, desprecio dominador, inmensa ligereza.

Identificar algunas de sus causas no es difícil, lo que es, moralmente hablando, imposible es repartir con justicia las cargas del esfuerzo para ver qué parte es mayor.

La primera de estas tensiones se expresa en una aguda conciencia de clase o grupo que abulta con exceso los derechos propios y las obligaciones de los otros, falta la visión de lo recto en la proporción de los esfuerzos.

Formada la clase y aislada del todo social afirma, por ejemplo, la desigual retribución del resultado del trabajo para continuar en unos los derechos de los amos o para considerarse los otros como los siempre oprimidos.

Las clases encuentran dificultad en la comunicación por la enorme diferencia cultural y esa dificultad acrecienta la tensión entre los grupos.

Los rápidos procesos de transformación del mundo son también una fuente de siempre renovadas tensiones, porque el cambio cultural o social no es suficientemente rápido ni tiene la profundidad y dimensión que se necesita: existe simple y llanamente la voluntad de no cambiar, existe ese sopor que antes mencionamos o la abusiva protección de situaciones no siempre justamente adquiridas, $O$ existe en las comunidades el alegre $Y$ renovado esfuerzo de luchar por la armonía.

Tensión por la conciencia de clase, tensión por la ineptitud para cambiar, existe además otra fuente más - la más abundante y la más notoria-aunque no la más profunda entre todas las que generan tensiones sociales: la posesión de los bienes materiales que aseguran el dominio y el gozo por el hombre del mundo; estos bienes son ordenados o medidos por la ciencia que se llama Economía. Son los que llamamos bienes materiales que se compran y miden con dinero.

Se expresan estas tensiones, por ejemplo, en la estructura de los sa- 
larios, o en la desarmonía entre la Agricultura y la Industria, o en la función atribuída por unos $u$ otros grupos al Estado y a los dineros del Estado.

Enumerar las tensiones no es aliviarlas; ni decir las fuerzas que pujan para establecer la armonía es el medio de señalar cuál es esa armonía o el camino para ella.

Para el hombre de hoy se presenta una gran alternativa en el camino de la paz: se ha de obtener por la evolución ordenada o es la revolución la que debe establecerla?

No hay en este planteo ningún alineamiento político: hay la presentación de dos posiciones culturales y sociales que tratan de resolver un problema.

No es su discusión lo que se me ha pedido; debo, sin embargo, decir que tengo una opción hecha. Pienso, con respeto a las opiniones de los otros y con el temblor interno que estas cuestiones vitales sentidas con hondura producen, que el camino de la paz es el de la evolución integral del hombre.

Esa evolución comporta "desarrollo"; como fases del proceso evolutivo, va poniendo el énfasis en cada uno de sus momentos sobre la múltiple exigencia que el "desarrollo" tiene.

Nuestro quehacer ahora es ver cuál es en la situación actual del mundo la suma de las tareas concretas que la Universidad tiene frente al desarrollo.

\section{La Universidad y el desarrollo}

Si los problemas del desarrollo se van a resolver de una manera. imaginativa e inteligente, no podrá hacerse sin las Universidades que son las fuentes indispensables de los hombres educados, el depósito de las aptitudes técnicas y de la habilidad intelectual requerida para encontrar $y$ trasladar a la realidad las mejores soluciones.

La participación de la Universidad en el desarrollo asegura un respeto para la totalidad de los problemas y la integridad de las soluciones. Esto no se consigue sin embargo $\sin$ un compromiso total de la Universidad de tal manera que todas sus facultades, toda su perspectiva intelectual, toda su sabiduría, se refleje en el problema.

Reflexionemos como cada una de las partes de la Universidad puede contribuir al desarrollo, especialmente en sus aspectos educativos y culturales, tomados estos conceptos en su más rico y comprensivo significado.

Hablemos primero de la Tecnología, no porque es más importante sino porque su aplicación es más inmediata y más extensa en las diversas dimensiones que el desarrollo tiene.

En su "Discusión sobre la Técnica", Friedrich Dessauer ha expuesto con inmensa claridad este papel sin igual de la técnica en su esfera de realizaciones y sin igual también en su significado como vehículo comprensivo de la cultura.

Para expresar la visión de la técnica como tarea ética y cultural resume las posiciones en las siguientes ideas.

- Esté donde esté el individuo, todos nosotros estamos profundamente penetrados de la idea de que la técnica jamás puede ser más 
que una tarea ética y cultural de cuyo cumplimiento es responsable en especial cada persona.

- La responsabilidad moral y humanitaria de todo hombre es el valor superior que debe abarcar todo lo técnico y encontrar eco en la técnica, en cuanto creadora y portadora de la cultura.

- Dada esta concepción, en el futuro no se podrá ya elevar el reproche de que la técnica, en cuanto tal, debe ser hecha responsable de la destrucción de valores externos e internos.

- La técnica encuentra su ethos en el respeto al orden de los valores. La técnica no es ni el único ni el supremo valor. La técnica es servidora de los valores superiores. Por encima de los valores vitales del hombre están los valores espirituales de lo verdadero, bueno $\mathrm{y}$ bello, los valores sagrados de lo religioso $\mathrm{y}$ por encima de todos, la última meta y fin de todas las cosas: Dios...

- La técnica sirve inmediatamente a los valores vitales del hombre $y$. en primer lugar, a su existencia corporal. Crea nuevas posibilidades de vida para miles de millones de hombres y a la vez libera al hombre de la opresora servidumbre del trabajo. Hace posible una alimentación cada vez mejor y aumenta la libertad del hombre gracias a una evidente abundancia de bienes de consumo. Vence de modo apenas imaginable el espacio y el tiempo. Incluso el peor enemigo de la técnica tiene que reconocer que puede servir admirablemente al hombre...

- Es el apartarse del orden moral lo que convierte a la técnica en enemiga del hombre. Toda técnica es obra humana. Cuando hablamos, pues, del carácter demoníaco de la técnica nos referimos propiamente a lo demoníaco del corazón humano cuando abusa de ella. Mós terrible que el pelear con las fuerzas de la materia es la lucha del hombre con su propia alma...

Es comprensible el entusiasmo por lo técnico cuando se piensa cuanto ha contribuido $y$ debe contribuir aún para liberar a los hombres de la servidumbre de la ignorancia, de la enfermedad, del hambre, la desnudez - falta de habitación.

Una segunda y muy importante Facultad de la Universidad, con gran significación para el desarrollo, es la de Economía.

El desarrollo no es exclusivamente un asunto de economía pero no hay desarrollo sin una sólida base económica; el recargo de instituciones ancestrales que perpetúan el estancamiento económico es muchas veces uno de los problemas básicos de los países.

Entre las cosas desequilibradas por las modernas tensiones sociales están: la desigualdad de ingresos, ineptitud de salario para satisfacer las necesidades vitales, distancias culturales $\mathrm{y}$ sociales provocadas por el retraso cultural, falta de iniciativa $Y$ espíritu de empresa que traslada al Estado todo el cuidado de la persona, etc.; fácil es ver como un serio progreso económico resuelve muchas de estas causas de tensión social.

La aplicación de las leyes económicas al manejo de las organizaciones dentro de lo que en el concepto moderno se llama la administración y organización de empresas, es también atro de los qrandes objeti vos de las Facultades de Economía.. 
De modo especial la cooperación internacional y su significación para el aligeramiento de las tensiones sociales por medio de la cooperación económica internacional, debe ser uno de los objetos de investigación y trabajo de las Facultades de Economía.

La tensión social tiene naturalmente un campo referido por su misma definición a la Facultad de Sociología. Pienso, por ejemplo, en todas las leyes de la dinámica social y en la urgencia de investigarlas en países en los que es necesario incrementar la movilidad social para vencer la inercia de estamentos convertidos en estratos.

De las diversas leyes que conforman el conocimiento sociológíco, hemos mencionado las de la dinámica, pero hay otras también como las del cambio social, la formación y conciencia de grupo y las aplicaciones de estas leyes a asuntos como la demografía, la transculturación, la aculturación, etc.

En muchos países la primacía del Derecho es aún mantenida no sólo como mero atavismo cultural, sino como expresión de auténticos valores culturales y morales. Es innegable que el Derecho debe expandir el campo de su acción a ese complemento y enriquecimiento de la persona que es su dimensión social, acrecida e iluminada por las múltiples luces de los estudios contemporáneos.

La Literatura, la Historia, como las Humanidades en general, tienen también un papel inmenso en este esfuerzo de esclarecer, aliviar $\underline{y}$ preparar las soluciones que la Universidad puede aportar a las tensiones sociales; reservo sin embargo las reflexiones últimas para tres Facultades que en orden de importancia reflejan lo más alto, lo más noble, y lo más comprensivo del esfuerzo humano por el bienestar social.

Son estas tres Facultades: la de Educación, la de Filosofía y la de Teología.

Si la Universidad tiene sentido, si nuestras reflexiones han podido encontrar un campo diverso de la mera dialéctica intelectual $y$ distinto también de la mera constatación de hechos sin encontrarles causa o sentido, es porque creemos en la misión y el poder de la educación.

La loa, la urgencia y la extrema importancia de la educación han sido repetidors en todos los niveles y lo que es inmensamente más significativo ha sido comprendida en todos los niveles, aún los menos educados de la sociedad. Guardo como recuerdo imborrable de mi vida el de una fría tarde cuzqueña cuando visitaba los "Baños del Inca"; un joven, o un niño de 13 a 14 años, indio puro con los profundos ojos de su raza llenos de vida, se acercó a nosotros, conversé con él: me preguntó si volvíamos al Cuzco, adelantó su deseo con gracia y viveza: ¿podríamos llevarlo? En el viaje nos contó que era pastor durante el día y al caer la tarde, cuando guardaba el rebaño, caminaba por los atajos de sus Andes más de hora y media hasta el Cuzco, asistía a una escuela vespertina de 8 a 10 y vuelta recorría su camino cuando era claro y de lucientes estrellas como aquel día pero también cuando era frío, lluvioso $y$ azotado por la tormenta.

Para mí ese niño es un símbolo que veo realizarse en los adultos que asisten a clases en la Escuela vespertina del Colegio donde vivo: uno de mis amigos en ella es un chofer de 53 años, padre de 6 hijos. 
La educación es como el pan, los hombres hoy la buscan con afán tanto más acrecido cuanto es mayor la necesidad que tienen de ella.

Leo con inmenso interés en la declaración de principios que agrupan a las Universidades en su búsqueda de la paz: "La Universidad ha de reconocer como parte importante de su formación educacional la de atender a los niveles educacionales primario y secundario, únicos en que se mueve la mayoría de los que llegan a tener alguna educación. Cumple esta función educacional al contribuir al curriculum de esos niveles, incrementando así la comprensión mundial".

¡No fué siempre así!

Preocupada la Universidad de la alteza del saber no ha buscado con empeño la vinculación con lo real que brota precisamente de las zonas vitales del contacto tales como la educación de las masas.

Hay más: una arbitraria clasificación de funciones ha dado, en muchas partes, a la rama ejecutiva del poder la función no sólo de ejecutar las cosas que se refieren a la educación pública, sino la de estudiarla, mejorarla, fijar sus contenidos, etc., etc.; Y para esta labor, repito por desinterés de la Universidad y también por excesivo celo del poder, no ha habido la colaboración que es vitalmente necesaria.

La educación recibe hoy un nuevo trato, para usar del lenguaje cortesano, $y$ vemos como los economistas se acercan a ella $\mathrm{y}$ la tratan con los términos de mercado, capital o producción: y aún después de la fuerte vacuna de 4 semanas pasadas en París en un Seminario sobre Economía y Educación, frases como las de este párrafo son tan desarmoniosas para mí como un grito en un concierto: "La formación de capital se ha considerado como un problema de expandir el almacenazgo de capital físico como por ejemplo, instrumentos, máquinas, materiales de producción, conexiones y servicios".

"Esto es lo más extraordinario porque la educación es y tiene una parte en el concepto más clásico de formación de capital. Las inversiones que se dedican a la educación producirán su rendimiento económico sólo después de un largo plazo en el futuro y deben ser distraídas de la producción de bienes inmediatos de consumo. El periodo de producción del capital humano es más largo que el de la mayoría de los componentes de una fábrica o de un equipo cualquiera y sugieren la necesidad de más cuidadoso planteamiento a largo plazo de inversiones en hombres aue inversiones en cosas tísicas".

No puede la Universidad moderna desconocer estas tendencias y estos análisis del moderno lenguaje $\mathrm{Y}$ del esfuerzo de muchos hombres que hoy tienen inmensa significación en la vida de las naciones. Debe la Universidad incorporar éste a los otros esfuerzos que la universalidad de su nombre reclama para llegar a la totalidad de que es también símbolo y expresión su nombre.

Lo que nos lleva más cerca de nuestra reflexión final: lo específico, lo propio de la Universidad no es la Economía o la Educación, sino la Economía y su referencia a la totalidad de los problemas de la cultura o de la vida del hombre.

Cómo salvar esta totalidad? Cómo asegurar esa integridad? Las ciencias que tienen esa misión se llaman Teología y Filosofía. Hay que 
reiterar consistentemente su misión pero hay también que hacerla cumplir.

Cada cultura tiene un centro creador; desde ese centro brota la acción auténtica del hombre sobre el hombre, y estar en ese centro, trabajar desde él, conlleva responsabilidades inmensas.

Hay un centro creador en cada cultura: en él están los artistas como los pensadores que no se alejan de la realidad sino que están listos siempre a enfrentarla, la realidad es algo del presente: nunca están contentos con descripciones del pasado o con ideas recibidas. Ellos batallan con la realidad de su grandeza que impresiona $y$ en su inesperada novedad, en sus problemas no resueltos como en su misterio no sondeado. Su batalla es creadora. Permiten que preguntas que no les dan descanso surjan unas después de otras, y enfrenten con valentía cualquier reto o cualquier empresa que llega casi a hacerles la vida imposible.

A ese centro pertenece la Filosofía tanto como la Teología: forman las pruebas intelectuales de este aserto, la historia misma del pensamiento de los hombres: con algún detenimiento he querido citar a Heráclito para enhebrar los hilos del razonamiento de esta tarde: y de los documentos sobre la paz que han conmovido recientemente al mundo puedo citar el es. tudio teológico del Papa Juan XXIII: "La paz en la tierra".

Desdo ese centro brota la acción auténtica sobre el hombre, la acción política es externa como lo es la economía o la guerrera; la acción de las ideas y en las ideas traslada a los sentimientos el querer y el hacer su fuerza, que es la de la persona misma.

Estar en ese centro conlleva responsabilidades, no puedo extenderme, pero deseo subrayario, pensar, crear, avanzar en la búsqueda, no se hace $\sin$ esfuerzo y sin riesgo. La universidad debe estar en ese centro o no muy alejada de él. Los que crean en filosofía, los que entienden y transmiten la palabra de Dios al mundo, deben estar en ese centro y deben estar en la Univesidad.

El eco insistente del pasado que resuena en el pensar filosófico o teológico puede ser una de las causas de su alejamiento del centro de influencia, pero es también cierto que la distancia de la Universidad es ese mismo centro es porque no ha dado en su sede, relieve e importancia $\alpha$ la Filosofía y a la Teología.

La paz es la aspiración profunda de los hombres de hoy, la paz será obra de la influencia cultural y humana de quienes piensan; si la Universidad no está cerca de ellos, no los tiene en su seno, no ayuda, como es su misión, a buscar de nuevo y empezar otra vez a buscar la paz.

Bienvenida esta oportunidad de recordar a todos nuestra misión. 